\title{
TINY RHIZOMORPHIC ROOTING SYSTEMS FROM THE EARLY PERMIAN ABO FORMATION OF NEW MEXICO, USA
}

\author{
Alexander J. Hetherington, ${ }^{1, *}$ William A. DiMichele, + Spencer G. Lucas, $¥$ and Sebastian Voigt§
}

\begin{abstract}
*Department of Plant Sciences, University of Oxford, South Parks Road, Oxford OX1 3RB, United Kingdom; tDepartment of Paleobiology, National Museum of Natural History, Smithsonian Institution, Washington, DC 20560, USA; ¥New Mexico Museum of Natural History, 1801 Mountain Road NW, Albuquerque, New Mexico 87104, USA; and §Urweltmuseum GEOSKOP/Burg Lichtenberg (Pfalz), Burgstrasse 19, Thallichtenberg D-66871, Germany
\end{abstract}

Guest Editor: Alexandru M.F. Tomescu

\begin{abstract}
Premise of research. Extant Isoetes species, which all develop small pseudoherbaceous habits, are the only living remnants of the once diverse clade of rhizomorphic lycopsids, which included trees that grew to towering heights of $50 \mathrm{~m}$. Although the rhizomorphic lycopsids evolved a range of diverse body plans in the Paleozoic, it is thought that the evolution of the small pseudoherbaceous habit, with small rooting systems similar to modern Isoetes species, was a late event in the clade's history, occurring in the Mesozoic. Here we describe small fossilized rooting systems from the early Permian Abo Formation of New Mexico, increasing our knowledge of the diversity of small Paleozoic rhizomorphic rooting systems.
\end{abstract}

Methodology. Ten fossilized rooting systems are described from a slab collected from the early Permian Abo Formation of New Mexico.

Pivotal results. Here we report 10 rooting systems interpreted as those of rhizomorphic lycopsids due to the presence on each of a large number of isotomously branched rootlets radiating from a central rhizomorph and two associated microphyll leaf impressions. Because of the fossils' tiny size (the largest rhizomorph is only $1.5 \mathrm{~cm}$ in diameter, and the largest rooting system, including rootlets, is only $6 \mathrm{~cm}$ in diameter), we interpret these fossils either as juvenile plants or as adult morphologies with a small rooting system. Given the paucity of mature rhizomorphic lycopsids in the Abo Formation and the limited fossil record of juvenile rhizomorphic lycopsids from any geological period, we predict that these are most likely to be adult plants with small rooting systems.

Conclusions. The small size of the specimens described here increases our knowledge of the diversity of small rhizomorphic rooting systems in the Paleozoic before the radiation of the modern Isoetes growth habit during the Mesozoic.

Keywords: Isoetes, lycopsids, Permian, roots, rhizomorph.

\section{Introduction}

The rhizomorphic lycopsids (DiMichele and Bateman 1996) are a hugely diverse group of plants with an evolutionary history spanning the mid-Devonian (ca. $387 \mathrm{Ma}$ ) to the present day (Phillips and DiMichele 1992; Pigg 1992, 2001; Skog and Hill 1992; Stewart and Rothwell 1993; Grauvogel-Stamm and Lugardon 2001; Xu and Wang 2016). Although extant Isoetes are small pseudoherbaceous plants only centimeters in height (Paolillo 1963), their Paleozoic relatives could grow to colossal heights of $50 \mathrm{~m}$ (Thomas and Watson 1976; Stewart and Rothwell 1993) and were anchored to the substrate by giant

\footnotetext{
1 Author for correspondence; email: sandy.hetherington@plants.ox .ac.uk.

Manuscript received August 2018; revised manuscript received November 2018; electronically published May 30, 2019.
}

rooting axes extending $15 \mathrm{~m}$ from the trunks of large trees and covered in rootlets (Williamson 1887; Stewart and Rothwell 1993; Hetherington et al. 2016). The group reached its ecological dominance during the Carboniferous Period (ca. 360$300 \mathrm{Ma}$ ) when many species were key components of wetland forests during the Early and Middle Pennsylvanian (Phillips and DiMichele 1992; DiMichele 2014).

After the Carboniferous, rhizomorphic lycopsids still played key roles in terrestrial ecosystems (Pigg 1992, 2001; Skog and Hill 1992; Stewart and Rothwell 1993; Grauvogel-Stamm and Lugardon 2001), but they did not achieve the same stature or ecological importance as they had earlier. In a general sense, therefore, the evolution of the rhizomorphic lycopsids is marked by a decrease in size from the giants of the Paleozoic that were tens of meters high, to the small arborescent forms in the Mesozoic that were only a couple of meters high (e.g., Pleuromeia), and finally to the forms that resembled modern Isoetes (e.g., Isoetites), which have been only a few centimeters high (Ash and 
Pigg 1991) from the Mesozoic to the present. This decrease in stature is seen most strikingly with the decrease in stem elongation and the transition of the rooting system from large axial branching rhizomorph axes (Williamson 1887; Frankenberg and Eggert 1969) to both unbranched axial axes and cormose forms (such as extant Isoetes species; Paolillo 1963; Rothwell and Erwin 1985; Pigg 1992, 2001; Grauvogel-Stamm and Lugardon 2001).

We now know that the evolution of the rhizomorphic lycopsids was more complex than previously assumed and did not involve a direct reduction series from giant arborescent trees to small pseudoherbaceous forms (reviewed by Pigg 1992). Instead, the fossil record preserves evidence of the coexistence of lycopsids with diverse growth habits and of both unbranched axial and cormose rhizomorphs having earlier origins than previously thought (Phillips and Leisman 1966; Pigg and Rothwell 1979; Jennings et al. 1983; Pigg and Taylor 1985; Pigg 1992, 2001; Xu and Wang 2016). However, despite the diversity of growth habits known from the Paleozoic, it appears that the origin of the small pseudoherbaceous habit typical of modern Isoetes was a comparatively late innovation. Plants with a habit similar to extant Isoetes with cormose rhizomorphs of only a few centimeters in diameter and reduced stem axial elongation are known only from the Triassic (Pigg 1992, 2001; Retallack 1997; Grauvogel-Stamm and Lugardon 2001). This late origin of the pseudoherbaceous growth habit of Isoetes is important as it hints that plants with modern growth habits, and therefore the ecologies that accompany them, evolved only in the Mesozoic despite a long Paleozoic history of the clade. The Mesozoic rhizomorphic lycopsids may therefore be thought of as "weedy survivors" of the Permian-Triassic extinctions (Retallack 1997). Here we report the discovery of small fossilized rhizomorphic rooting systems from the lower Permian of New Mexico. These rooting systems increase our knowledge of the diversity of rhizomorphic lycopsids with small rooting systems from the Paleozoic, before the evolution of the modern growth habit of Isoetes during the Mesozoic.

\section{Material and Methods}

\section{Geological Locality}

In central New Mexico, siliciclastic red beds of the lower Permian Abo Formation (Wolfcampian to early Leonardian) record fluvial deposition during the last stages of the ancestral Rocky Mountain orogeny (Lucas et al. 2014). In the Cerros de Amado-Joyita Hills area of Socorro County, the Abo Formation contains a significant record of continental plant fossils (DiMichele et al. 2013), vertebrate fossils (Berman et al. 2015), and prolific assemblages of red bed (Scoyenia ichnofacies) trace fossils representing both vertebrates and invertebrates (Hunt and Lucas 2015).

The slab documented here was collected in the Cerros de Amado-Joyita Hills area. It is housed in the New Mexico Museum of Natural History and Science (NMMNH) in Albuquerque, New Mexico, and catalogued as NMMNH P-25887. It was collected at NMMNH locality 3250, which is a sandstone bed stratigraphically high in the upper member (Cañon de Espinoso Member) of the Abo Formation, ca. $8 \mathrm{~m}$ below the overlying Arroyo de Alamillo Formation of the Yeso Group (fig. 1).
Given its stratigraphic position, NMMNH locality 3250 is almost certainly of early Leonardian age (Lucas et al. 2015). Other fossils found at, and near, NMMNH locality 3250 are impressions of walchian conifers and tetrapod footprints (fig. 1).

DiMichele et al. (2013) reviewed the Abo Formation paleoflora based on collections made from ca. 200 localities. This paleoflora is of low diversity and dominated by fossils of walchian conifers and of the peltasperm Supaia.

\section{Results}

The slab containing the fossils is roughly rectangular (ca. width $28 \mathrm{~cm}$, height $21 \mathrm{~cm}$ ) and is ca. $1 \mathrm{~cm}$ deep (fig. 2). The most prominent features on the surface of the slab are 10 roughly circular, and in some cases overlapping, structures (fig. $2 B$, labeled 1-10). Because of their apparent in situ position on the bedding plane, we interpret the structures as rooting systems. Each rooting system consists of a similar overall organization (figs. 2, 3): roughly circular and ca. 4-6 cm in diameter (based on measurement of the specimens that are completely preserved; fig. $2 B, 1-5,8,10)$ and protruding slightly above the surface of the bedding plane. At the center of each rooting system is a roughly circular region of ca. $1-1.5 \mathrm{~cm}$ in diameter that either protrudes farther from (fig. $2 B, 1,3-5,7,8$; fig. 3 ) or is indented into (fig. $2 B, 2,10$; fig. 3 ) the rock surface. The central region, which we will refer to as the rhizomorph (fig. 3 ), is not fully preserved (fig. 2B, 6, 9). Where the central rhizomorph forms a depression in the surface, there are no further defining features (fig. 2B, 2, 10; fig. 3A, 3B). By contrast, in the examples where the central rhizomorph protrudes above the rock surface, further detail is preserved (fig. $2 B, 1,3,4,7,8$; figs. $3 C, 3 D, 4$ ). The rhizomorph (fig. $3 C, 3 D$ ) appears as a raised tier and is the highest part of the rooting system above the bedding surface (fig. 4B, 4E, 4I). The details of the central rhizomorph are not well preserved. However, in each case the region is marked by an angular indent (fig. 3C, 3D) that is either triangular (fig. 4C, $4 F, 4 G$ ) or a four-point-star shape (fig. $4 J$ ) at the center.

Radiating in all directions from each central rhizomorph is a large number of frequently branched linear structures, preserved as indentations in the rock surface; these structures are darker in color than the surrounding matrix. These linear structures are blunt tipped. They are relatively uniform in diameter between branch points and decrease in diameter with each dichotomy, which is isotomous. The central rhizomorph lacks these branched structures. Because of their point of initiation at the periphery of the central rhizomorph and their highly branched nature, we interpret these linear structures as rootlets (fig. 3). The lateral extent of the rootlets marks the periphery of the circular rooting systems (fig. 3). Rootlets frequently branch as they radiate from the central rhizomorph, and one rootlet developed at least three orders of branching (fig. $2 B$, black arrow; fig. $5 A, 5 B$ ). Rootlet networks may overlap where they occur at high densities on one plant or where they emanate from plants preserved close to each other (fig. 2B, 3-5, 7-9). The rootlets radiate in all directions from the rhizomorph, forming a concentric circle (fig. 3). Unfortunately, the connection of the majority of rootlets cannot be traced back to the rhizomorph, making it impossible to determine the structure of the meristem from which they developed or their rhizotaxy. 


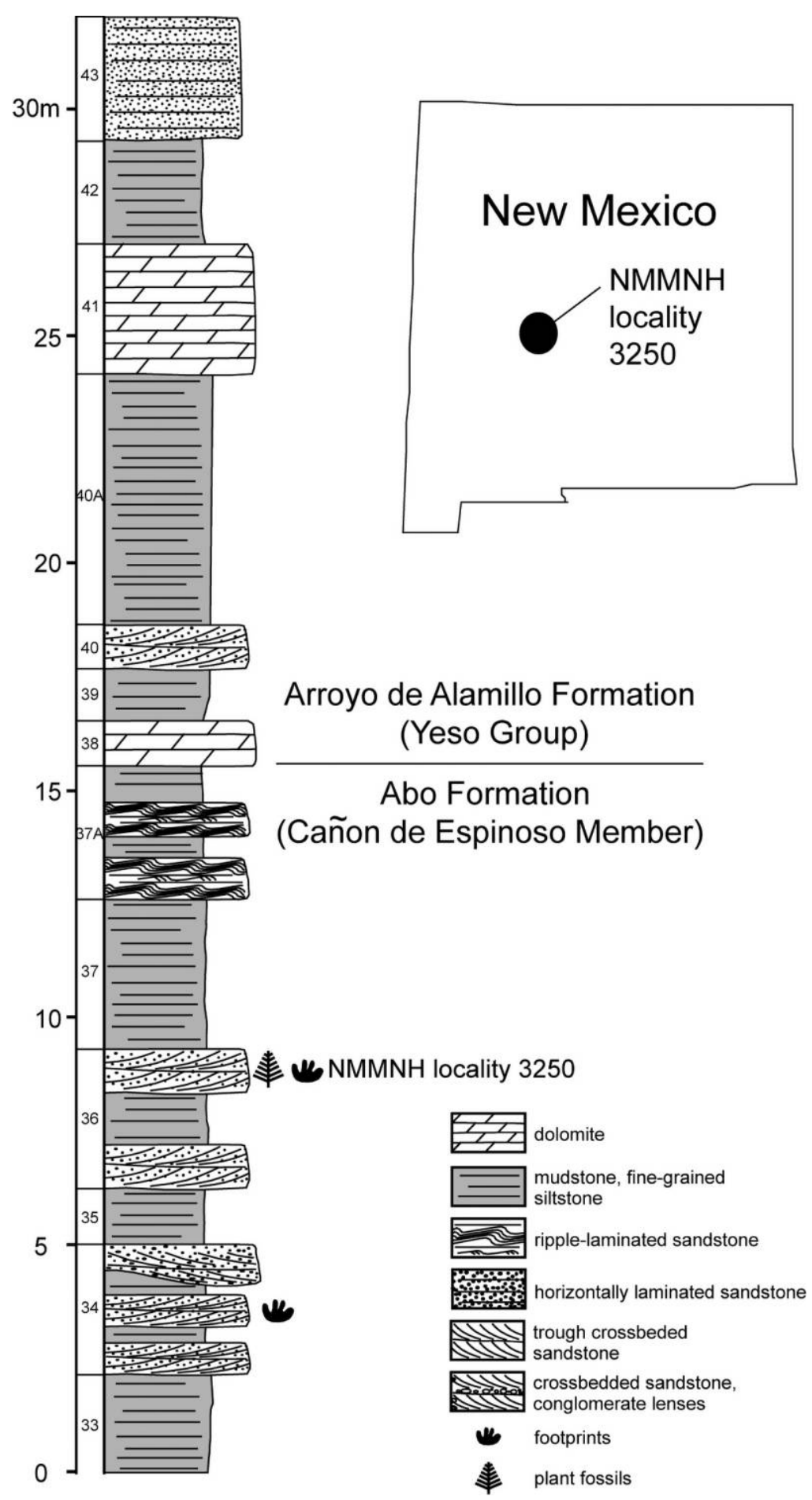

Fig. 1 Stratigraphy of the Abo Formation (New Mexico) showing the location of NMMNH locality 3250 where the slab NMMNH P-25887 was collected.

The lower surface of the slab displays no circular rooting structures. The regions that directly correspond to the rooting structures on figure $2 A$ (labeled $1-10$ on fig. $2 B$ ) do not show evidence of the continuation of the rhizomorph or of the surrounding network of rootlets. This suggests that the rooting sys- tems described in figure $2 A$ do not penetrate the depth of the slab.

In summary, the rooting systems preserved on the slab are roughly circular overall and consist of two parts: first, a roughly circular central rhizomorph that varies in its preservation be- 

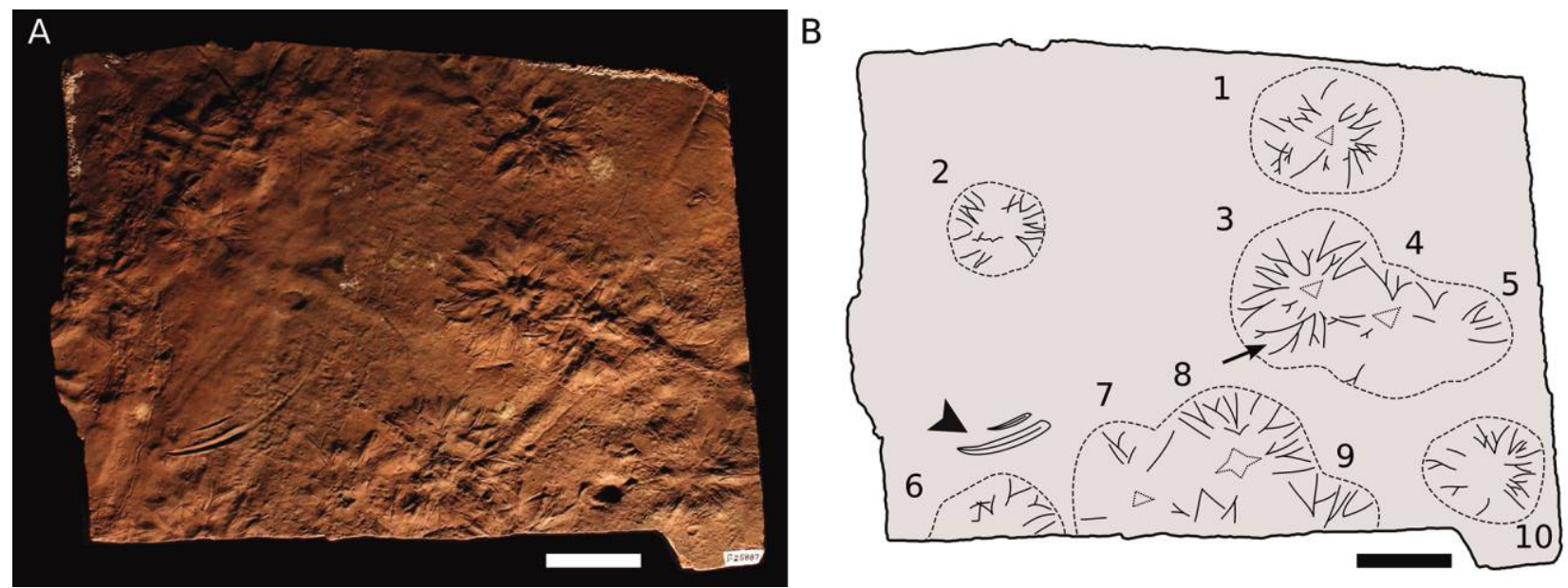

Fig. 2 Permian rhizomorphic rooting systems. A, Surface of the slab NMMNH P-25887, showing evidence of 10 roughly circular rooting systems and two associated leaf impressions. $B$, Schematic of the major features of the bedding surface, showing impressions of 10 roughly circular rooting systems (1-10). Note that rooting systems 6 and 9 are only partially preserved. The impressions of two leaves shown in figure $5 C$, $5 D$ are highlighted with an arrowhead. The branched rootlet shown in figure $5 A, 5 B$ is highlighted with an arrow. Lighting: $A$, diffuse lighting from multiple directions with predominant lighting from bottom right of the image. Scale bars $=4 \mathrm{~cm}$.

tween the specimens and, second, radiating from this central rhizomorph, a large number of isotomously branched rootlets (fig. 3).

In addition to the rooting systems preserved on the slab (fig. 2A), there are impressions of two tapered linear structures with slightly curved shapes and pointed tips, which we interpret as leaves (highlighted with an arrowhead in figs. $2 B, 5 C, 5 D$ ). Both leaf impressions have a similar structure, although they differ in size (the larger leaf is ca. $3.5 \mathrm{~cm}$ long, the smaller leaf ca. $1.5 \mathrm{~cm}$; fig. $5 C, 5 D)$. Both are marked at the center by a central linear impression running the length of the leaf (fig. $5 \mathrm{C}$, $5 D)$. This central keel is consistent with the leaf having a single central vascular trace, a characteristic feature of the microphylls of rhizomorphic lycopsids. Apart from these detached microphylls, there is no other evidence of the anatomy of the aboveground shoot systems.

\section{Discussion}

The diagnostic feature of the rooting systems described here is a large number of isotomously branched rootlets radiating in all directions from a central rhizomorph (fig. 3). Roots that branch strictly isotomously are a characteristic feature of both extinct and extant lycopsids (Hetherington and Dolan 2017). Thus, the highly isotomously branched rootlets support the hypothesis that the fossils are the rooting systems of lycopsids. The prediction of lycopsid affinity is further supported by the associated leaf impressions (fig. 5C, 5D), both of which possess a single central keel consistent with a single leaf trace running along the center of the leaves. This trace is a diagnostic feature of the microphylls of lycopsids (Kenrick and Crane 1997); leaves with this morphology are not typical of any other group of plants from the Euramerican Pennsylvanian or Permian age. Therefore, by association, these leaves support the lycopsid affinity of the rooting systems. A large number of rootlets, developed in high density from a central rhizomorph, is a charac- teristic feature of the rhizomorphic lycopsids (DiMichele and Bateman 1996). We therefore interpret these fossilized rooting systems as having affinities with that group of plants. Given that the central rhizomorphs show no evidence of branching (figs. 24), we interpret the central rhizomorphs as either unbranched and axial or cormose in structure. Furthermore, because the central rhizomorphs do not penetrate the slab, this suggests that these may have been shallowly buried rooting systems. Rhizomorphic lycopsids that developed axial or cormose rhizomorphs are known to both pre- and postdate the early Permian age of these fossils (Phillips and Leisman 1966; Pigg and Rothwell 1979; Jennings et al. 1983; Pigg and Taylor 1985; Pigg 1992, 2001; Skog and Hill 1992; Stewart and Rothwell 1993; Retallack 1997; Grauvogel-Stamm and Lugardon 2001; Xu and Wang 2016). However, these rooting systems are of interest due to their particularly small size.

The most striking feature about the rooting systems preserved on the slab, when compared to the rooting systems of many other rhizomorphic lycopsids, is their small size. The maximum diameter of the largest rhizomorph is only $1.5 \mathrm{~cm}$, and the maximum diameter of the largest rooting system, including rootlets, is only $6 \mathrm{~cm}$. These rooting systems are, therefore, much smaller than most of the rhizomorphic rooting systems known from the Carboniferous (Jennings et al. 1983; Pigg and Rothwell 1983; Pigg 1992, 2001). The closest similarity in size is the small rhizomorph described for Cormophyton mazonensis, with a width of $2.6 \mathrm{~cm}$ (Pigg and Taylor 1985; Pigg 1992). In their size, the Abo Formation specimens are similar to rooting systems of the pseudoherbaceous forms known from the Triassic onward (Pigg 1992, 2001; Retallack 1997; Grauvogel-Stamm and Lugardon 2001).

We propose two explanations for the small size of these plants: either they are juvenile plants of much larger rhizomorphic lycopsids or they are adult rhizomorphic lycopsids with small rooting habits. If they are juvenile plants, they represent some of the few examples discovered that preserve the early ontogeny 

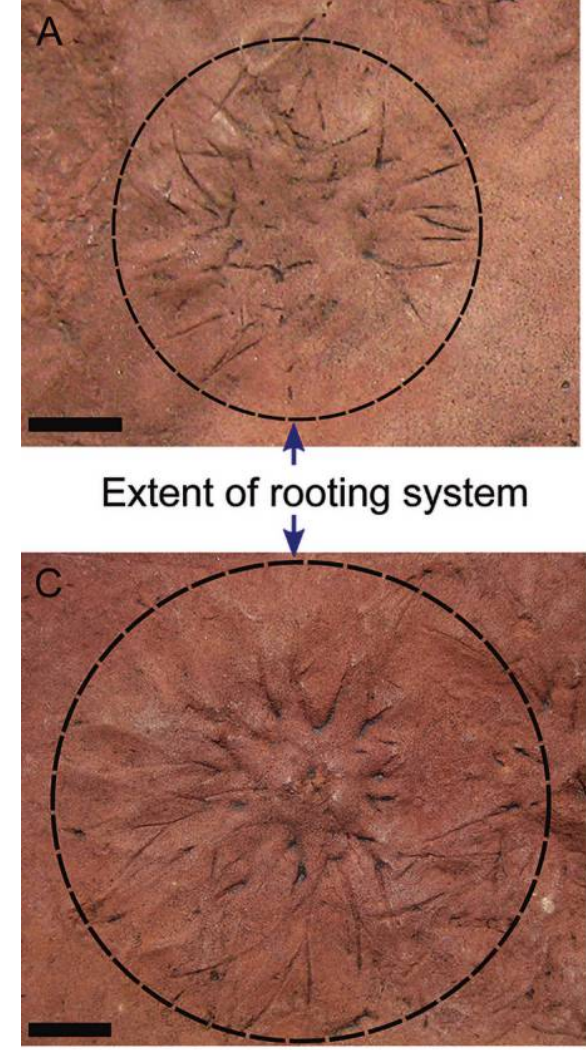

\section{centin}

Fig. 3 Interpretive diagram of rhizomorphic rooting systems. $A$, Image of specimen 2 from figure $2 B$ with the extent of the rooting system highlighted. $B$, Interpretive diagram of $A$, highlighting the lateral structures interpreted as rootlets and the central region hypothesized to represent the rhizomorph. $C$, Image of specimen 3 from figure $2 B$ with the extent of the rooting system highlighted. $D$, Interpretive diagram of $C$, highlighting the lateral structures interpreted as rootlets and the central region hypothesized to represent the rhizomorph, including the central angular indent. Lighting: $A, C$, vertical lighting from above. Scale bars $=1 \mathrm{~cm}$.

of rhizomorphic lycopsids (Karrfalt 1984; Boyce and DiMichele 2016), connecting developing spores (Phillips 1979) with larger mature specimens (MacGregor and Walton 1948; DiMichele and DeMaris 1987; Stewart and Rothwell 1993). The lack of arborescent lycopsid remains (in which periderm and wood would more likely be preserved than in immature specimens) in the Abo Formation (DiMichele et al. 2017), combined with the elusive nature of juvenile rhizomorphic lycopsids in the fossil record (Boyce and DiMichele 2016), makes the juvenile-arborescent hypothesis the less likely of the two options. Alternatively, if the fossils are adult plants, they increase our knowledge of Paleozoic rhizomorphic lycopsids with small rooting systems. Unfortunately, the rhizomorph morphology is not well preserved, making it impossible to determine whether these plants had a cormose or axial rhizomorph. Furthermore, although the rhizomorphs do not extend through the depth of the slab, implying that they were shallowly buried, we have no evidence of the nature of the aboveground shoot system. Based on these lines of evidence, we predict that these plants were shallowly buried adult morphologies with small rhizomorphic rooting systems.

Despite the poor preservation of the fossils, it is possible to speculate on the structure of their rhizomorphs. In support of

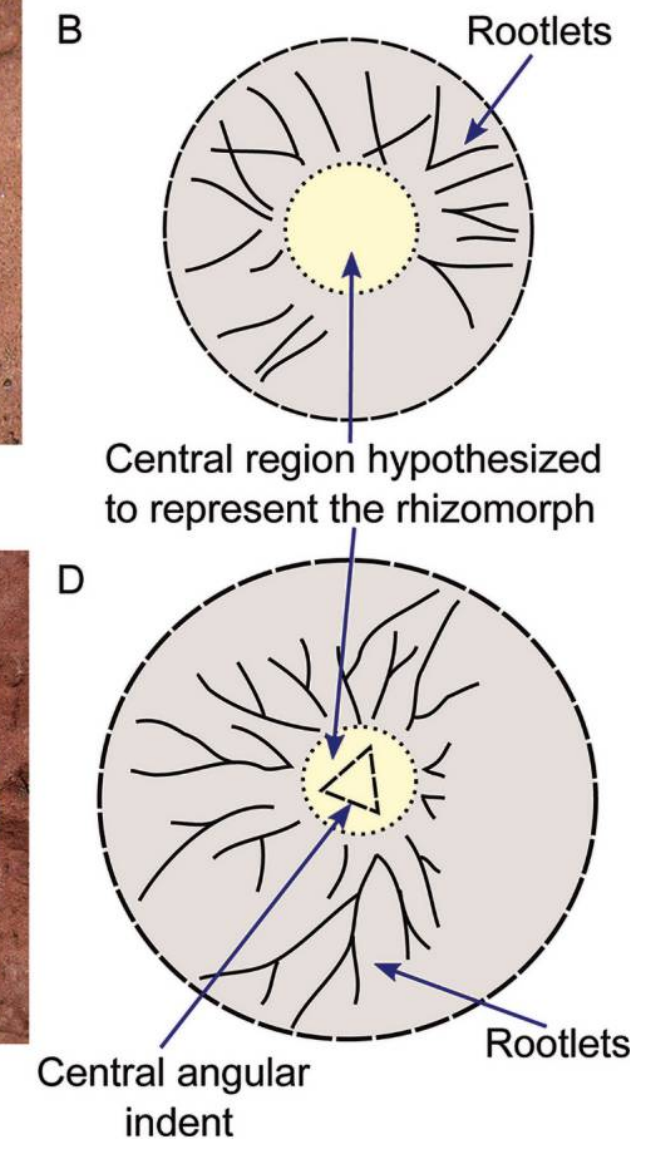

the rhizomorphs being unbranched and axial is the observation that the rootlets form a concentric circle around the roughly circular region interpreted as the rhizomorph (figs. 2-4). If the plants developed unbranched axial rhizomorphs, they may have had a growth habit similar to Paurodendron fraipontii (Phillips and Leisman 1966; Rothwell and Erwin 1985). Alternatively, it is possible that these rooting systems are small cormose forms more typical of the Mesozoic (Pigg 1992, 2001; GrauvogelStamm and Lugardon 2001). Very tentative evidence for the cormose nature of these fossils comes from the triangular and star-shaped marks at the center of the rhizomorphs (figs. 3, $4 C, 4 F, 4 G, 4 J)$. The base of a three-lobed rhizomorph such as Isoetes nuttallii (Karrfalt and Eggert 1978) or of a four-lobed rhizomorph such as Pleuromeia sternbergii (Grauvogel-Stamm 1993) would leave a triangular or star-shaped impression, respectively. However, this interpretation seems unlikely as we would expect to find evidence of the meristematic furrows within the triangular or star-shaped indentation (Karrfalt and Eggert 1978; Grauvogel-Stamm 1993). Until further specimens are discovered, it is not possible to reach conclusions about the nature of the rhizomorphs or the complete interpretation of the habit of these plants. 

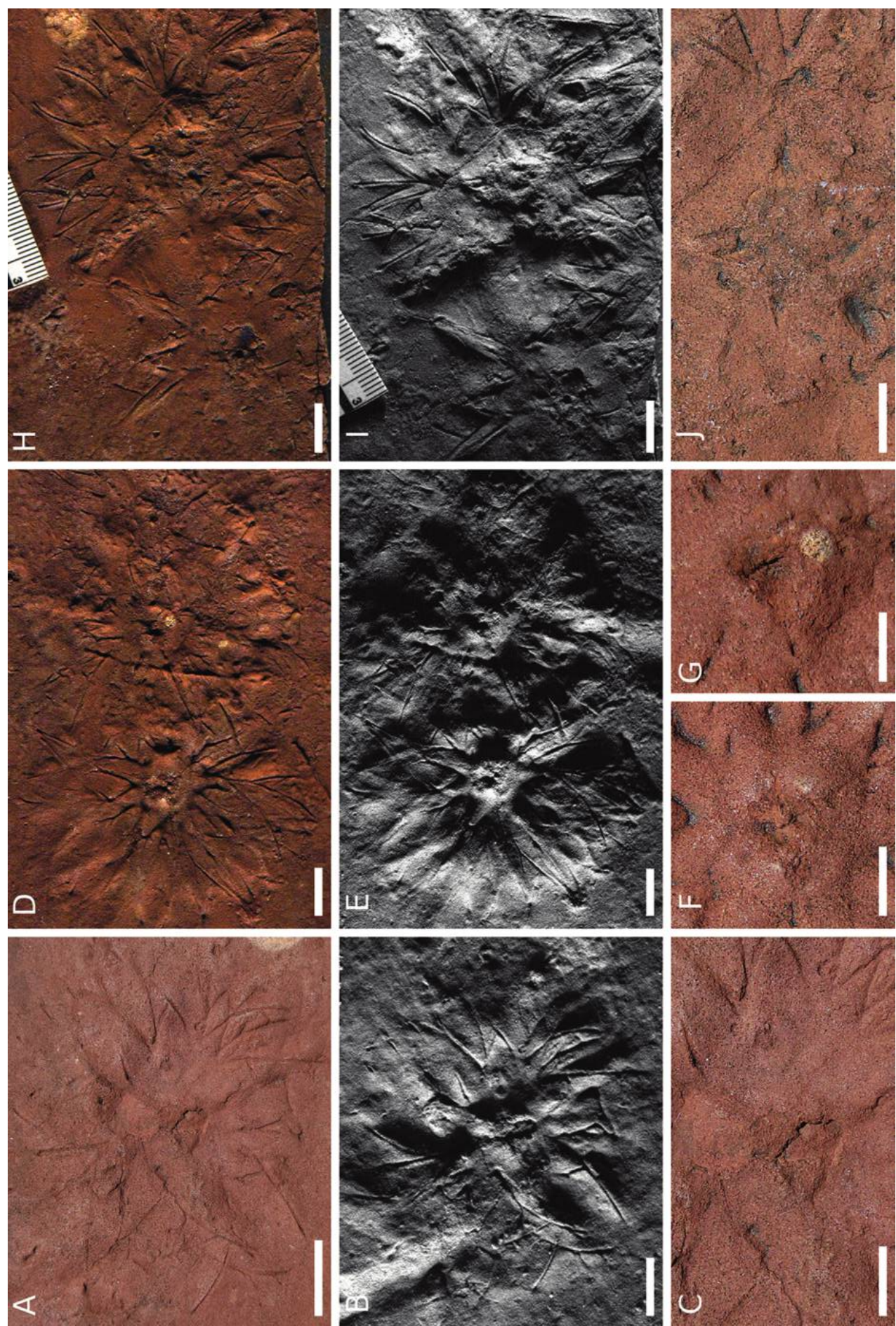

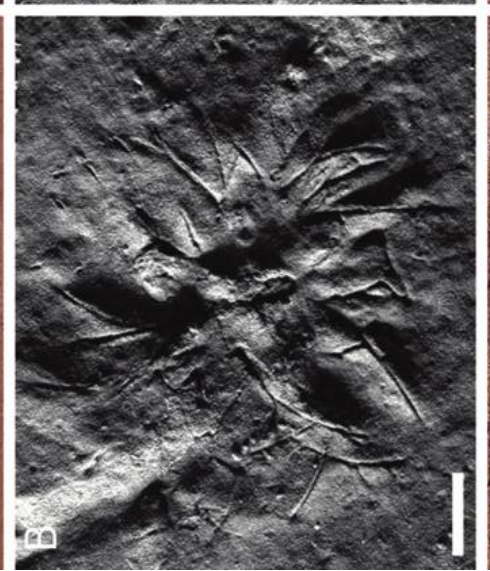

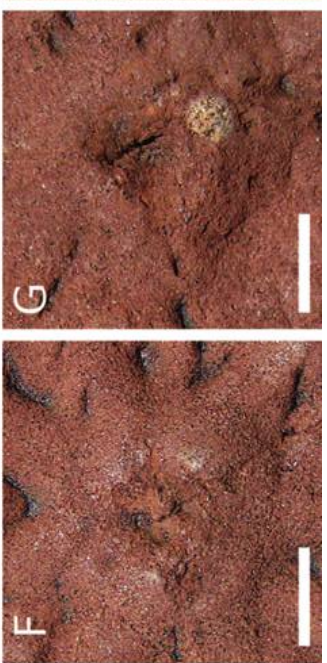

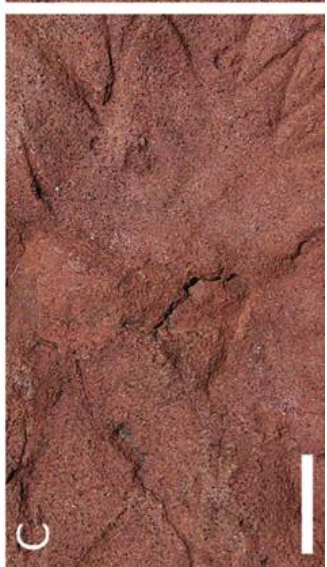

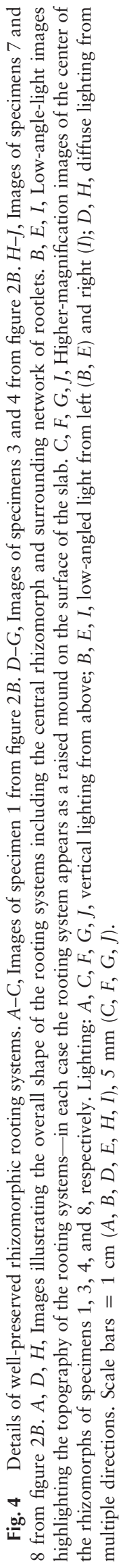



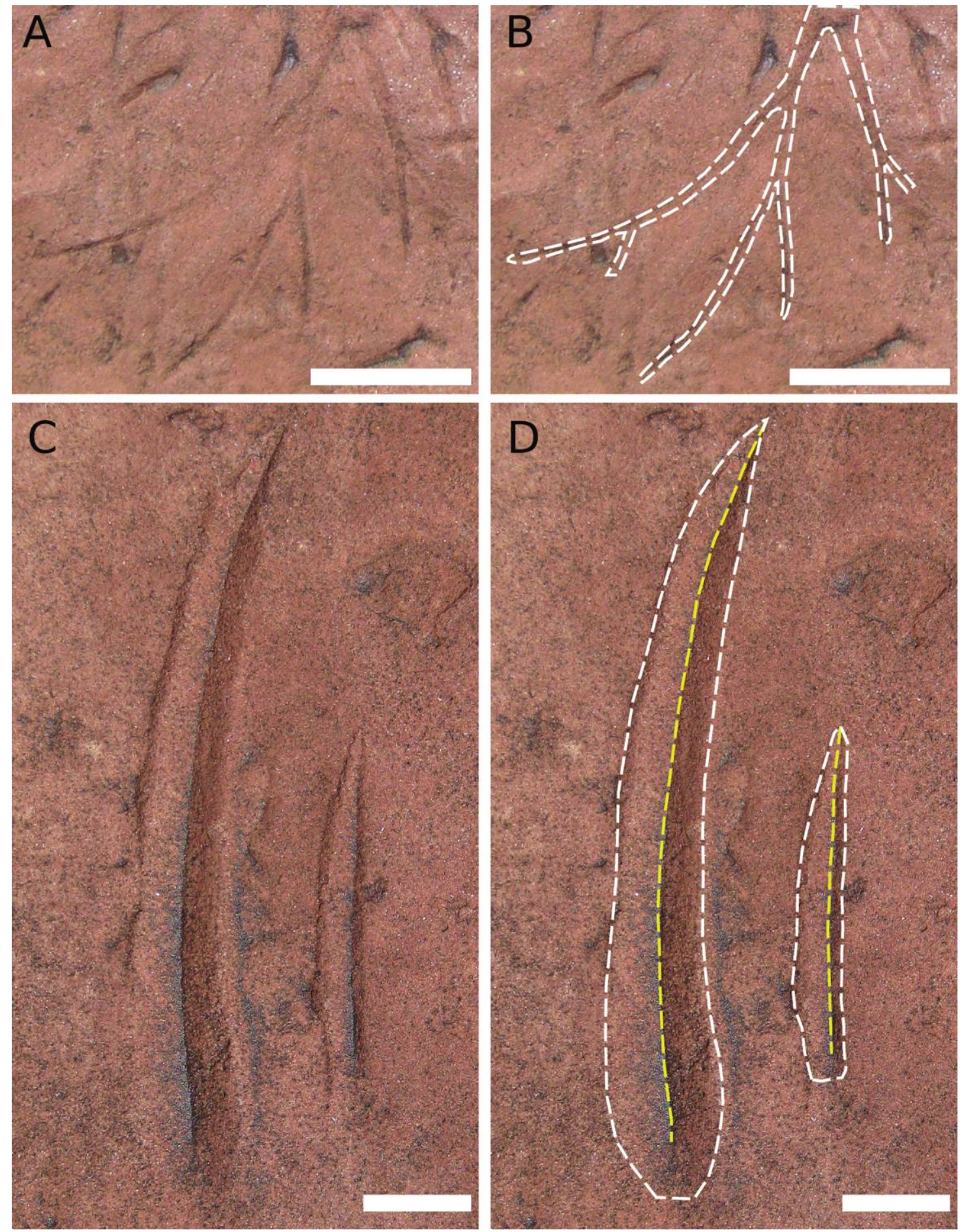

Fig. $5 A$, Highly branched rootlet highlighted with an arrow in figure $2 B$. $B$, Same image as $A$ with dashed white lines highlighting the outline of the branched rootlet. $C$, Impression of two microphylls highlighted with an arrowhead in figure $2 B . D$, Same image as $C$ with dashed white lines highlighting the outline of the microphyll and dashed yellow lines highlighting the position of the central keel. Lighting: vertical lighting from above. Scale bars $=1 \mathrm{~cm}$.

Despite the limited preservation of these small rhizomorphic rooting systems, their discovery is intriguing as it suggests that a cryptic diversity of rhizomorphic lycopsids with small rooting systems was present during deposition of the Abo Formation.
This cryptic diversity may reflect, in part, the low preservation potential and high likelihood of early erosion of so much of the terrestrial landscape, permitting a great deal of evolutionary history to escape capture in the geological record (Looy et al. 
2014). The Abo Formation itself has been intensely sampled for plant, animal, and ichnofossils for several decades, and just recently, the first occurrence of the calamitalean foliage Annularia was discovered there (DiMichele and Lucas 2017). This type of foliage is very common and widely distributed throughout the Euramerican tropics during the Pennsylvanian and Permian, and yet it remained unknown in the Abo Formation until this discovery, demonstrating the complexities of rarity in nature versus rarity in the fossil record. The findings reported here as well as the previous discovery of Annularia (DiMichele and Lucas 2017) highlight the importance of continued fieldwork to document the entirety of a fossil flora in the Abo Formation.

\section{Conclusions}

Here we report the discovery of a slab containing 10 rooting systems preserved in early Permian strata. Based on the diagnostic anatomy of the rooting systems (a large number of isotomously branched rootlets radiating from a structurally complex central region; fig. 3) and associated leaf impressions (with a single leaf trace per leaf; fig. 5), we interpret the rooting systems as belonging to members of the rhizomorphic lycopsids. The central rhizomorphs show no evidence of branching, leading us to conclude that the rooting systems were from plants that produced either cormose or unbranched axial rhizomorphs.
Although both cormose and axial rhizomorphs pre- and postdate the occurrence of these fossils, it is the size of the fossils that makes them interesting. The small size of the specimens indicates that these plants were either juveniles of larger tree forms or mature plants with small rooting systems. Given the absence of mature, arborescent rhizomorphic-lycopsid remains in red beds of the Abo Formation and the elusive nature of juvenile rhizomorphic lycopsids in the fossil record, we suggest that these remains most likely represent mature plants of a very small size. The small size of these specimens increases our knowledge of small rhizomorphic rooting systems in the Paleozoic before the origin of the small Mesozoic forms (Pigg 1992, 2001), as well as broadening the list of taxa present in the Permian flora of the Abo Formation.

\section{Acknowledgments}

We would like to dedicate this manuscript to Gar W. Rothwell for his numerous, wide-ranging contributions to the understanding of plant evolutionary history. We are grateful to two reviewers as well as the guest editor Alexandru M.F. Tomescu for insightful comments on our manuscript. A. J. Hetherington was funded by the George Grosvenor Freeman Fellowship by Examination in Sciences, Magdalen College, Oxford.

\section{Literature Cited}

Ash SR, KB Pigg 1991 A new Jurassic Isoetites (Isoetales) from the Wallowa terrane in Hells Canyon, Oregon and Idaho. Am I Bot 78:16361642 .

Berman DS, AC Henrici, SG Lucas 2015 Pennsylvanian-Permian red bed vertebrate localities of New Mexico and their assemblages. N M Mus Nat Hist Sci Bull 68:65-76.

Boyce CK, WA DiMichele 2016 Arborescent lycopsid productivity and lifespan: constraining the possibilities. Rev Palaeobot Palynol 227:97-110.

DiMichele WA 2014 Wetland-dryland vegetational dynamics in the Pennsylvanian ice age tropics. Int I Plant Sci 175:123-164.

DiMichele WA, RM Bateman 1996 The rhizomorphic lycopsids: a case-study in paleobotanical classification. Syst Bot 21:535-552.

DiMichele WA, DS Chaney, SG Lucas, H Kerp, S Voigt 2013 Flora of the lower Permian Abo Formation redbeds, western equatorial Pangea, New Mexico. N M Mus Nat Hist Sci Bull 59:265-287.

DiMichele WA, PJ DeMaris 1987 Structure and dynamics of a Pennsylvanian-age Lepidodendron forest: colonizers of a disturbed swamp habitat in the Herrin (No. 6) Coal of Illinois. Palaios 2:146-157.

DiMichele WA, SG Lucas 2017 The first specimen of Annularia spinulosa Sternberg from the lower Permian Abo Formation, New Mexico, and implications for rarity in the plant fossil record. N M Mus Nat Hist Sci Bull 77:17-23.

DiMichele WA, SG Lucas, CV Looy, H Kerp, DS Chaney 2017 Plant fossils from the Pennsylvanian-Permian transition in Western Pangea, Abo Pass, New Mexico. Smithsonian Contributions to Paleobiology 99. Smithsonian Institution, Washington, DC.

Frankenberg JM, DA Eggert 1969 Petrified Stigmaria from North America. I. Stigmaria ficoides, the underground portions of Lepidodendraceae. Palaeontogr Abt B 128:1-47.

Grauvogel-Stamm L 1993 Pleuromeia sternbergii (Münster) Corda from the Lower Triassic of Germany-further observations and com- parative morphology of its rooting organ. Rev Palaeobot Palvnol 77:185-212.

Grauvogel-Stamm L, B Lugardon 2001 The Triassic lycopsids Pleuromeia and Annalepis: relationships, evolution, and origin. Am Fern _ 91:115-149.

Hetherington AJ, CM Berry, L Dolan 2016 Networks of highly branched stigmarian rootlets developed on the first giant trees. Proc Natl Acad Sci USA 113:6695-6700.

Hetherington AJ, L Dolan 2017 The evolution of lycopsid rooting structures: conservatism and disparity. New Phytol 215:538-544.

Hunt AP, SG Lucas 2015 Vertebrate trace fossils from New Mexico and their significance. N M Mus Nat Hist Sci Bull 68:9-40.

Jennings JR, EE Karrfalt, GW Rothwell 1983 Structure and affinities of Protostigmaria eggertiana. Am I Bot 70:963-974.

Karrfalt EE 1984 Further observations on Nathorstiana (Isoetaceae). Am I Bot 71:1023-1030.

Karrfalt EE, DA Eggert 1978 The comparative morphology and development of Isoetes L. III. The sequence of root initiation in threeand four-lobed plants of I. tuckermanii A. Br. and I. nuttallii A. Br. Bot Gaz 139:271-283.

Kenrick P, PR Crane 1997 The origin and early diversification of land plants: a cladistic study. Smithsonian Institution, Washington, DC.

Looy CV, H Kerp, IAP Duijnstee, WA DiMichele 2014 The late Paleozoic ecological-evolutionary laboratory, a land-plant fossil record perspective. Sediment Rec 12:4-18.

Lucas SG, K Krainer, DS Chaney, WA Dimichele, S Voigt, DS Berman, AC Henrici 2014 The lower Permian Abo Formation in the northern Sacramento Mountains, southern New Mexico. N M Geol Soc Guideb 65:287-302.

Lucas SG, K Krainer, D Vachard, S Voigt, WA DiMichele, DS Berman, AC Henrici, JW Schneider, JW Barrick 2015 Progress report 
on correlation of nonmarine and marine Lower Permian strata, New Mexico, USA. Permophiles 61:10-17.

MacGregor M, J Walton 1948 The story of the fossil grove of Glasgow Public Parks and Botanical Gardens, Glasgow. Glasgow Public Parks and Botanic Gardens Department, Glasgow.

Paolillo DJ 1963 The developmental anatomy of Isoetes. University of Illinois Press, Urbana.

Phillips TL 1979 Reproduction of heterosporous arborescent lycopods in the Mississippian-Pennsylvanian of Euramerica. Rev Palaeobot Palvnol 27:239-289.

Phillips TL, WA DiMichele 1992 Comparative ecology and life-history biology of arborescent lycopsids in Late Carboniferous swamps of Euramerica. Ann Mo Bot Gard 79:560-588.

Phillips TL, GA Leisman 1966 Paurodendron, a rhizomorphic lycopod. Am I Bot 53:1086-1100.

Pigg KB 1992 Evolution of isoetalean lycopsids. Ann Mo Bot Gard 79:589-612.

2001 Isoetalean lycopsid evolution: from the Devonian to the present. Am Fern I 91:99-114.

Pigg KB, GW Rothwell 1979 Stem-root transition of an Upper Pennsylvanian woody lycopsid. Am I Bot 66:914-924.
1983 Chaloneria gen. nov.: heterosporous lycophytes from the Pennsylvanian of North America. Bot Gaz 144:132-147.

Pigg KB, TN Taylor 1985 Cormophyton gen. nov., a cormose lycopod from the Middle Pennsylvanian Mazon Creek flora. Rev Palaeobot Palvnol 44:165-181.

Retallack GJ 1997 Earliest Triassic origin of Isoetes and quillwort evolutionary radiation. I Paleontol 71:500-521.

Rothwell GW, D Erwin 1985 The rhizomorph apex of Paurodendron: implications for homologies among the origins of Lycopsida. Am I Bot 72:86-98.

Skog JE, CR Hill 1992 The Mesozoic herbaceous lycopsids. Ann Mo Bot Gard 79:648-675.

Stewart W, GW Rothwell 1993 Paleobotany and the evolution of plants. 2nd ed. Cambridge University Press, Cambridge.

Thomas BA, J Watson 1976 A rediscovered 114-foot Lepidodendron from Bolton, Lancashire. Geol I 11:15-20.

Williamson W 1887 A monograph on the morphology and histology of Stigmaria ficoides. Palaeontogr Soc 40:1-62.

Xu H-H, Y Wang 2016 The earliest cormose rhizomorph of putative lycopsid affinity from the Middle Devonian of West Junggar, Xinjiang, China. Rev Palaeobot Palvnol 226:54-57. 